\title{
The Building of Speaking Right of Marxist Ideology in the Network Era
}

\author{
Shengli Chen \\ Luohe Medical College \\ Luohe,462000 China
}

\begin{abstract}
The network is a new field of ideology and culture blending and ideological conflict. Marxist ideology and value of science have not been obscured in the new media virtual space and time, but instead highlight the urgency and necessity of the construction of Marxist ideology right to speak. We should pay attention to social development and public life, optimize Marxism content ideological discourse, integrate traditional media and network resources, cultivate Marxist ideological discourse platform, master propagation and mass psychology, innovate Marxist ideological discourse exchange mechanism, strengthen monitoring and institutional norms of discourse, and actively expand health orderly and reasonable discourse space.
\end{abstract}

\section{Keywords- Network; Marxism; the Right to Speak}

\section{VALUE DIMENSIONS OF MARXIST IDEOLOGY RIGHT TO SPEAK IN A NETWORK ERA}

The network media, mobile media as the main forms of new media, have become an important part of public life. High expression, high speed of information dissemination, volume and other information led to social and psychological characteristics, viability and recognition of the value of a formula. To adhere to the principle of the unity of theory and practice is the correct understanding of science and the value in new media environment of Marxist ideology and is the epistemological premise of speaking right to explore the construction of Marxist ideology.

\section{A. Guide the Public from the "Herd Mentality" to "Public Reason"}

People are social animals, group behavior and herd mentality is the norm of society. In the new media environment, diversification of the main network discourse and the discourse of content easily lead to complicated other non-rational "herd mentality" phenomenon, causing the network group incidents and emergencies, affecting social stability. Marxist ideology in circumvention "herd mentality" phenomenon and nurture scientific public reason has important significance.

Internet era "herd mentality" phenomenon influences social order. Herd mentality is generated by the convergence of personal information and behavior outside influence. Internet era is with the diversification of the main discourse, the complex content of information, dissemination disorder, individualism, utilitarianism, moral pluralism, history and other social thought nihilism permeate into people's lives, people's judgment and discernment in the face of declining false information, network rumors. They lost value, the value of the confusion, the value of frequent injustice. individuals are more susceptible to cognitive networks misleading rumors, false information, negative from the mouth of the "herd mentality "phenomenon causes the network group incidents, emergencies frequently, reducing the credibility of the government, affecting normal order of society and impact. Therefore, how to guide the public out of the negative "herd mentality" toward positive, calm and rational and positive social attitude is to follow the scientific public reason, which has become the new media environment, publicity and ideological work commitments pending tasks.

Modern Marxist ideology boosts scientific discourse and foster public reason. Scientific group of public reason is unconscious digestion. We should maintain normal social order of an important foundation. In the public sphere, the science of public reason is different from the instrumental rationality of Western culture, the practical rationality of traditional culture and modern Western public reason. Science major public reason is to advocate social individuals and social groups to consciously accept and endorse the core values of the Marxist ideology, which is based on the core values of socialism. It is a tolerant and friendly, positive way to deal with social spear crumbs and value conflicts, with communication and consultation mechanisms, such as democracy and the rule of law in the form of proper regulations to express their views, ideas and opinions. Since the Party Congress, the Marxist theory of ideology constantly enrich the connotation of socialist core values from the state, as well as civil society level to clarify the value of norms and values and ideals of socialism with Chinese characteristics. The socialist concept of honor is to establish people's ethics and guidelines. We need efforts to safeguard the right to speak of Marxist ideology, help to make the public conscious recognition of social rules and values, raise awareness of social thought, false rumors of judgment, discernment. So that people can be with calm and rational, healthy and friendly, positive attitude to express their views, attitudes, opinions through legitimate interests expression mechanism, communication and consultation mechanisms and channels of democratic rule of law. It is to help eliminate bait social conflict, promote social harmony, to maintain good social order. 


\section{B. Promote the Public by "Technological Alienation" to "Comprehensive Development"}

Network virtualization is a new eco-environment of individual existence; the release of spatial freedom is bringing the spirit of joy, but making individual into a "technical alienation" crisis of survival. Therefore, under the new media situation, the construction of Marxist ideology discourse is aimed at arming people with scientific theories, and at promoting people out of the "technological alienation," the survival of the state, to achieve free and full development.

In the Internet age, there is "technological alienation" problem, as Marx pointed out: "Object labor produces, namely the product of labor is as an alien being, as a producer he does not rely on power, as opposed to the same labor."Network is the product of human civilization and social progress, and its popularization and application to a certain extent to expand the breadth of global exchanges and promote the development of social productive forces. It also brings a person" technical alienation "problem. Network as a fast and convenient science and technology quickly spreads to the nature of public life. The individual gradually technology is an extension of the body and mind, accept. Even it is used to rely on network technology, people gradually "lost both natural movement function, they lost the ability to directly intervene, because there is no better choice. It is entirely dependent on the sensor, sensory, and other kinds of long-range detection capability, these capabilities will be his, and he became enslaved to talk to machine beings, "human language ability, athletic ability will increasingly subside, the body structure will also be changed. New media as a popular culture is concerned. It has changed people's lives and the life force of a content type, fragmentation and any of the content of discourse deconstructs the critical spirit body. People are immersed in the culture of mass consumption of new media and entertainment among, which is to promote the relationship between man and nature, man and society, individual communication dwindles in a separate virtual environment, people become indifferent and lonely.

Modern Marxist ideology is to promote the right to speak human freedom and comprehensive development. Free and comprehensive development of the capitalist system and the demise of the communist regime are to achieve the ideal living conditions of future generations, but also the development goals of socialism with Chinese characteristics. Under the new media situation, people's "technical alienation" crisis is clearly contrary to the essential requirements of the socialist and communist values. Marxist ideology established the right to speak, in essence, is to promote the individual out of the "technological alienation" to promote the realization of human freedom and comprehensive development of the spiritual, cultural, and ideological education levels. In modern society, the Marxist ideology critique spiritual essence of the subject is to raise the discriminative ability and critical ability out of the deconstruction of popular culture on the subject of the new media environment, to prevent the individual lost in a herd mentality among the cultural and entertainment. Marxist ideology of science is reflected in its scientific concept.

Theory of armed people improves people's mental outlook and values to guide the development of social thought, to create a positive culture, so that people consciously pursue their full development.

\section{Achieve the Public by "Identity Missing" to "Citizen Identity"}

In the Internet age, complication of the digestion discourse content ideologies is reducing the authoritative content; the diverse body of discourse is reduced by ideological speech trust, causing the public to national, ethnic and political identity crisis. Value of Marxist ideology is manifested in the right to speak through the construction, so that people consciously recognized mainstream values and enhanced public acceptance of citizens.

Modern Marxist ideology is to promote the right to speak "citizen identity" formation. Ideology reflected specific social class interests of ideas superstructure, ideological discourse aimed at maintaining the right to construct the superstructure legitimacy and to achieve the interests of a particular class. Marxist ideology is the doctrine of the proletariat and the emancipation of the humankind, which represents the fundamental interests of the masses. Construction of Marxist ideology discourse in the network era helps make the masses personal experience of socialism with Chinese characteristic. The Chinese Communist Party and the people of the value point keep abreast with the Communist Party of China routes, which forces a needle and policies to enhance the broad masses of the people for the Chinese Communist Party and the masses of the socialist system with Chinese characteristics and identity. Under the new media situation, the Marxist ideology of scientific discourse constructs proper guidance to help promote its social thought, social media and social language ecology towards positive, calm and rational, healthy and harmonious atmosphere of development. So that the majority of the people can be out of ideological bias and wrong understanding, for the system it is to achieve the Chinese Communist Party and the socialist party Identification of Chinese identity.

\section{CONSTRUCTION PATH OF MARXIST IDEOLOGY DISCOURSE IN THE NETWORK ERA}

Network is a new communication carrier of Marxist ideology, the new changes in the mode of transmission and dissemination of the contents are weakening the explanatory power of the Marxist theory of ideology, reducing the degree of recognition of the people, but also highlighting the scientific construction of the Marxist ideological discourse right urgency and necessity. Therefore, to accurately grasp the rules and characteristics of network communication effectively plays a positive role in the new media, innovation Marxist ideology of communication, which can consolidate Marxist ideology discourse.

First, we should focus on social development and public life, and optimize the discourse content. Marx and Engels pointed out: "thoughts, ideas, consciousness are directly 
related to the production of the first people's physical activity, physical contact with people, and the language of real life intertwined 'ideological content creation figure to be concerned about the public's reality. Life is only close to the ideology of public life that was persuasive and charismatic network technology development and popularization, which is highlighting the human freedom) transition and autonomy, highlighting the life of the state and the individual values of the people, for the public to participate in public affairs and to express interest demands to provide a new platform. Therefore, the Marxist ideology of theoretical innovation has insight into the virtual world in which people want to diversify interest demands of the establishment of a network of public opinion of analysis commentary, estimation mechanism, statistics and analysis of new media in virtual spatial information content. Through scientific statistical and theoretical analysis, it is to detect widespread desire and attitude, to enhance Marxist ideological discourse of practical relevance and theoretical scientific. It is to focus on new media virtual existence in the hot air to ask questions and sensitive topic of public opinion with timely and objective analysis to assess public attitudes and public thought practical for secular life and difficult issues of innovation theory, principles, policies, Marxism lofty ideological discourse and reality, life of the organic unity. It is to change the ideological field theory innovative way of thinking, the theoretical innovation implements to focus on human life and promote human development level, which is to adhere to the people-oriented basic idea, to meet the majority of the people's spiritual and cultural needs for the purpose, respect and promotion of human round development.

Secondly, the integration of traditional media and new media resources are to build a platform to speak. Ideology and public discourse platform is a field blending of soul, field " also formed the ideological discourse in the popularization of Marxism dissemination activities, the technical elements of the importance of the spread of Marxism popularity has been unprecedented growth, becoming Marxism special To popularity spread. New media technologies and ideas gradually spread into the popularization of Marxism and its basic elements into the process. "In the Internet era, Marxist ideology discourse constructed to focus on nurturing platform. We must not only play the traditional ideological discourse platform effects, such as television, newspapers, radio, etc., but also allow the use of existing sub-sites, BBS forums, micro blog, SMS, timely publicity to spread the Marxist ideology theory. We should also allow the use of the emerging sub-mobile news, mobile phone TV, mobile TV, mobile websites, mobile phones, radio, television, video, network digital television, Internet broadcasting, micro blog, letters and other new media to establish and improve the propaganda website of Marxist ideology, government micro blog, and build a comprehensive Marxist ideological discourse platform. We should allow the use of new media divide large information capacity, informative and fast speed of information dissemination, information communication smooth features to graphics, text, sound, painting, video and other multimedia vivid manifestation of the image to spread Marxist ideology. So that we can make the people living close to the form, meet the spiritual needs of the people to enhance the charm of Marxist ideology discourse.

Finally, we should standardize system designed to strengthen the monitoring of discourse. Discourse monitoring can effectively reduce or control network rumors, false information, anti-Marxist ideology thought of breeding, can promote the formation of public calm and rational, positive, rational point of view, the social atmosphere and orderly expression, safeguard the legitimate Marxist ideology, leadership and the right to speak. In the Internet age, we are to establish a sound public warning monitoring mechanism, systematic collection, analysis, judgment, and feedback New Media virtual space under a new dynamic to ask the public thought, to detect false information, network rumors, and reactionary ideas. With the scientific application of Marxist theory, we can reveal its false reactionary nature, develop effective coping strategies to defuse public misunderstanding, and enhance the right to speak in Marxist ideology critique and respond in a positive manner.

\section{CONCLUSION:}

We should improve laws and regulations, build up strict accountability system, and actively promote the real-name authentication system in the Internet age. With the new media, we use scientific management to control public virtual spatial information. We should set up the establishment of an effective information system and accountability system to shield anti-Marxist ideas, antisocial irrational negative thoughts and punish acts like violation of laws and regulations. On the basis of protecting the legitimate rights and interests of Internet users, we should gradually increase the protection of Marxist ideology right to speak.

\section{References}

[1] Qiu Bosheng. Study status quo of China's political psychology of Fudan University (Social Sciences), 1996, (4): 89 a 91.

[2] Bi Tantao. Explore media revival of the Chinese Liberation Day] young reporter, 2008, (12): 14 a 16.

[3] Marx and Engels. Selected Works (1st Royal [M] Beijing: People's Publishing House, 199s.72.

[4] Lv Zhiguo. Talk about the new media environment Marxism popular propagation path field Ideological \& Theoretical Education, 2011, (9): 40 to 43 . 